alloys containing 81 to 87 per cent gold shows evidence of ordering reactions and it is virtually certain therefore that their hardening occurs by the same mechanism. Such studies also indicate that both palladium and tin can constitute a portion of the hardening second phase, depending on the iron to platinum content ratio. However, it appears that the best properties result from the use of a hardener (iron + cobalt + nickel) to platinum content ratio which is near unity on an atomic basis.

For dental applications there are definite advantages associated with alloy hardening by an ordering reaction. Since the kinetics of ordering are not limited by rates of diffusion, hardening occurs rapidly during cooling from the porcelain firing temperature. Thus, near-optimal hardness is obtained without there being any need to give specific attention to the number of firing cycles, porcelain firing temperature or cooling rate. The dental practitioners and dental laboratory technicians can therefore be assured of proper alloy hardness irrespective of the porcelain firing schedule which they use.

\section{Conclusions}

The reaction kinetics of age hardening in a high gold content ceramo-metal alloy have been examined in detail. Hardening has been shown to result from an ordering reaction with consequent rapid hardness increases during cooling from the porcelain firing temperature. It has also been shown that, contrary to previous assumptions, ordering of finely dispersed particles of an FePt-type compound causes hardening. The dispersed morphology of this second phase results in strengthening of the lattice through microstrains associated with ordering dilatation. For the particular alloy of this study the compound stoichiometry was found to be $\mathrm{PtFe}_{0.6} \mathrm{Co}_{0.3}$. The ordering reaction begins on air cooling from the porcelain firing temperature at approximately $850^{\circ} \mathrm{C}$ and reaches completion between 400 and $250^{\circ} \mathrm{C}$. For a dental alloy, the advantage of hardening by an ordering reaction lies in the insensitivity of the phenomenon to differences in porcelain firing schedules.

\section{References}

1 W. J. O'Brien, J. E. Kring and G. Ryge, f. Prosth. Dent., 1964, 14, $955-960$

2 K. F. Leinfelder, W. J. O'Brien, G. Ryge and C. W. Fairhurst, f. Dent. Res., 1966, 45, 392-396

3 D. L. Smith, A. P. Burnett, M. S. Brooks and D. H. Anthony, 7. Dent. Res., 1970, 49, 283-288

4 IMage, Patent Pending, The J. M. Ney Co., Bloomfield, CT., U.S.A.

5 G. V. Raynor in 'Physical Metallurgy', edited by R. W. Cahn, North-Holland, Amsterdam, 1965, pp. 291-363

$6 \mathrm{~J}$. S. Kouvel in 'Intermetallic Compounds', edited by J. H. Westbrook, John Wiley \& Sons, New York, 1967, pp, 529-568

7 W. B. Pearson, 'A Handbook for Lattice Spacings and Structures of Metals and Alloys', Pergamon Press, London, 1967

8 R. Hultgren, P. D. Desai, D. T. Hawkins, M. Gleiser and K. K. Kelley, 'Selected Values of the Thermodynamic Properties of Binary Alloys', American Society for Metals, Metals Park, OH., 1973

\title{
The Stereochemistry of Gold(I) Complexes
}

Gold is usually two-coordinate, both in its simple binary compounds such as its halides and in its coordination complexes, and a linear arrangement of ligands around the gold(I) atom has been demonstrated in many compounds of this type. However, with tertiary phosphines in particular, gold(I) forms complexes in which it displays higher degrees of coordination. With such ligands, for example, 2:1 complexes of the composition $\mathrm{AuXL}_{2}$ (X = an anionic ligand, $\mathbf{L}=$ a tertiary phosphine) are formed and have recently been characterized. In some cases they are ionic and contain a two-coordinate cation $\left(\mathrm{AuL}_{2}\right)^{+}$, especially where $\mathrm{X}^{-}$ is a weakly coordinated anion such as $\mathrm{ClO}_{4}^{-}$or $\mathrm{PF}_{6}^{-}$. In other cases the anion is coordinated to the gold and the gold atom is three-coordinate, as in the compound $\left[\mathrm{AuCl}\left(\mathrm{PPh}_{3}\right)_{2}\right] \cdot 0.5 \mathrm{C}_{6} \mathrm{H}_{6}$ of trigonal-planar structure.

Moreover, the coordination of more than two phosphine ligands to gold(I) in solution has been demonstrated by phosphorus-31 nuclear magnetic resonance spectroscopy. The best defined of these higher coordination complexes are those formed with triphenylphosphine $\left(\mathrm{PPh}_{3}\right)$, and solids of composition $\left[\mathrm{Au}\left(\mathrm{PPh}_{3}\right)_{\mathrm{n}}\right] \mathrm{ClO}_{4}(\mathrm{n}=2,3$ or 4 ) have been isolated (1), though their precise structures have not been determined.

Structural diagnoses can be readily made on such solid materials by gold-197 Mössbauer spectroscopy, and R. V. Parish and J. D. Rush of the Department of Physics of the
University of Liverpool have recently (2) applied this technique in a study of these latter complexes. They found that the Mössbauer parameters of the complexes were extremely sensitive to the number and nature of the ligands attached to the gold.

In the case of the complex $\left[\mathrm{Au}\left(\mathrm{PPh}_{3}\right)_{2}\right] \mathrm{ClO}$, these parameters were consistent with a linear two-coordination of the gold. A zero quadrupole splitting unambiguously confirmed a tetrahedral four-coordination for the cation in $\left[\mathrm{Au}\left(\mathrm{PPh}_{3}\right)_{4}\right] \mathrm{ClO}_{4}$. (With a d ${ }^{10}$ ion, the electric field gradient is determined entirely by the distribution of the ligands and is therefore zero for a tetrahedral configuration). The complex $\left[\mathrm{Au}\left(\mathrm{PPh}_{3}\right)_{3} \mathrm{CClO}_{4}\right.$ must involve trigonal threecoordination and the Mössbauer parameters were indeed consistent with its geometry being trigonal-planar.

Although these findings are not unexpected, they constitute a significant addition to our knowledge of complex formation by monovalent gold.

\section{References}

1 L. Malatesta, L. Naldini, G. Simonetta and F. Cariati, Coord. Chem. Rev., 1966, 1, 255-262

2 R. V. Parish and J. D. Rush, Chem. Phys. Lett., 1979, 63, (1), 37.39 